\title{
RAZONES DOGMÁTICAS QUE JUSTIFICAN Y SOLUCIONAN LA CONTROVERSIA SOBRE LA PUNIBILIDAD DEL "CÓMPLICE" INTERESADO EN EL DELITO DE TRÁFICO DE INFLUENCIAS
}

\section{DOGMATIC REASONS THAT JUSTIFY AND SOLVE THE CONTROVERSY ON THE PUNIBILITY OF THE "CÓMPLICE" INTERESTED IN THE CRIME OF TRAFFIC OF INFLUENCES}

\author{
Álvaro G. Espinoza Ramos ${ }^{1}$ \\ Bachiller en Derecho \\ Universidad de San Martín de Porres \\ red_black_85@hotmail.com
}

Perú

\section{SUMARIO}

- Introducción

- El delito de Tráfico de Influencias -Marco conceptual y Preliminar-

- La contraria concepción dogmática de la corte suprema en el Acuerdo Plenario $\mathrm{N}^{\circ}$ 03-2015 respecto de la punibilidad del interesado en el delito de tráfico de influencias

- El delito de tráfico de influencias es un delito de participación necesaria impropio, un delito monosubjetivo y un delito de encuentro

- Soluciones a la controversia doctrinal respecto de la punibilidad del cómplice interesado en el delito de tráfico de influencias

- Conclusiones

\section{RESUMEN}

El autor propone una solución dogmática para entender cuando es posible la punibilidad del cómplice interesado en el delito de tráfico de influencias; para ello, con mucha minuciosidad detalla las terminología correcta respecto de lo que debe entenderse como delitos de participación necesaria y delitos plurisubjetivos, haciéndose énfasis en la distinción de su contenido y relación; además, a través de esta precisión terminológica y de la armonización de los conceptos, el autor llega a la conclusión de que el delito de tráfico de influencias es un delito de participación necesaria impropio -monosubjetivo- y de encuentro, lo cual constituye, a juicio del autor, la solución principal a esta controversia que ya se ha venido discutiendo históricamente, tanto en el campo jurisprudencial de las decisiones como en la doctrina nacional.

\begin{abstract}
The author proposes a dogmatic solution to understand when it is possible the punishability of the accomplice interested in the crime of influence peddling; to do so, he carefully details the correct terminology regarding what should be understood as crimes of necessary participation and plurisubjective crimes, emphasizing the distinction of their content and relationship; In addition, through this terminological precision and the harmonization of concepts, the author concludes that the crime of influence peddling is a crime of participation necessary improper -monosubjetivo- and of encounter, which constitutes, in judgment of the author, the main solution to this controversy that has already been discussed historically, both in the jurisprudential field of decisions and in national doctrine.
\end{abstract}

1 Bachiller en Derecho por la Universidad de San Martín de Porres. Maestrista de la especialidad de Ciencias Penales por la misma casa de estudios. 


\section{PALABRAS CLAVE}

Delito monosubjetivo, Delito plurisubjetivo, Delito de participación necesaria propio, Delito de participación necesaria impropio, Cómplice interesado, Instigador interesado, Injusto de intervención.

\section{KEY WORDS}

Monosubjective Offense, Plurisubjective Offense, Crime of Own Necessary Participation, Crime of Necessary Improper Participation, Interested Accomplice, Interested Instigator, Unfair Intervention.

\section{INTRODUCCIÓN}

"El ignorante afirma, el sabio duda y reflexiona"

(Aristóteles).

Actualmente vivimos una crisis de corrupción, que golpea, no solo a los altos mandatarios de los países latinoamericanos (como en los casos de corrupción de "Odebrechet" que se vienen investigando por el Ministerio Público), sino, incluso ha venido siendo el mal endémico principal en el desarrollo de nuestra nación, puesto que, a raíz de los últimos audios que se han venido propalando de manera subrepticia por la prensa, se han verificado actos de corrupción no solo reprochables moralmente, sino también reprochables por el ius puniendi estatal, conductas de quienes eran llamados a impartir justicia, de quienes elegían a éstos, y de quienes aceptaban tal cargo sin merecerlo a través de medios corruptores. ${ }^{2}$

En esta pluralidad de audios, llama atención particular, uno de ellos por ser relevante como ejemplo en este breve artículo jurídico, en este audio en mención, considero que si estaríamos ante una conducta típica de corrupción (previa al cohecho), esto es, una conducta típica de tráfico de influencias, delito el cual, si bien conforme su configuración típica es un delito común y de dominio, no obstante, el desvalor de su resultado implica un peligro abstracto en la administración pública por el desvalor de la acción corrupta.

2 Entendiendo al problema de la corrupción como un mal habitual, general y arraigado, que ha calado hasta en los más ínfimos ámbitos de poder.
En efecto, en este audio en mención, un funcionario público (Juez Superior) solicita a un postulante al cargo de fiscal adjunto provincial un medio corruptor (dinero), a fin de que posteriormente, el primero de éstos, interceda en el procedimiento administrativo de su nombramiento (llevado a cabo ante otras autoridades administrativas), y se asegure así mediante esta venta de influencias su elección en el cargo.

En este supuesto de hecho, es evidente que el funcionario público que solicita un medio corruptor a fin de vender sus influencias ante la entidad administrativa que resolverá el procedimiento de elección o nombramiento de fiscales, y hace prometer tal medio corruptor per se al interesado en tal elección, cometería ineludiblemente una conducta típica de tráfico de influencias; empero, cabe preguntarnos, si el "cómplice interesado" en tal situación de elección sería impune, por el mero hecho de no estar prevista su conducta en el tipo penal o en otro tipo penal como sucede en los casos de cohecho (que si es un delito plurisubjetivo de participación necesaria).

A propósito de las razones dogmáticas de la punibilidad de este cómplice interesado en los delitos de tráfico de influencias, es sobre lo cual versa el presente artículo jurídico, el cual se compromete, a brindar dar pautas de solución dogmáticas respecto de la hasta ahora controversia acerca de la punibilidad del cómplice interesado en este tipo penal de tráfico de influencias, el cual es un delito de participación necesaria impropio-mono subjetivo y de encuentro.

Es de destacar, a fin de un mejor entendimiento del tema sobre el cual se circunscribirá este artículo jurídico, que las soluciones dogmáticas que propondré, versaran sobre la punibilidad del "cómplice" interesado, y no sobre la punibilidad del "instigador" interesado, puesto que, considero que tal concepción de punibilidad ya ha sido solucionada en el Acuerdo Plenario $\mathrm{N}^{\circ}$ 03-2015 de la Corte Suprema de la República.

Para el logro de tal objetivo planteado en la presente labor, en primer lugar se precisará un marco conceptual genérico respecto de que constituye un delito de tráfico de influencias (precisando sus diversas modalidades y en cuales de estas es posible la punibilidad del 
Dogmatic reasons that justify and solve the controversy on the punibility of the "cómplice" interested in the crime of traffic of influences

cómplice interesado), en segundo lugar se hará un análisis breve respecto del Acuerdo Plenario $\mathrm{N}^{\circ}$ 03-2015, realizándose una crítica al respecto de su contenido de entender, que no todos los que coadyuvan a la comisión del tipo penal de tráfico de influencias, pueden ser entendidos como instigadores, dado razones dogmáticas que se precisarán en el desarrollo de este capítulo; en tercer lugar, y como punto más importante, se detallará porque el tipo penal de tráfico de influencias (tal como se encuentra configurado por nuestra legislación), es un tipo penal de participación necesaria impropio-mono subjetivo, y de encuentro, -cuestión principal en la solución de esta controversia-, brindándose para ello, una clasificación de los delitos de participación necesaria establecida por este autor, la cual zanjará los problemas y errores que ha venido teniendo la doctrina nacional al interpretar al delito de tráfico de influencias como un delito de participación necesaria y plurisubjetivo, por último, y habiéndose entendido que estamos en el delito de tráfico de influencias ante un tipo penal de participación necesaria impropiomono subjetivo, y de encuentro, y no ante un delito plurisubjetivo como mal ha entendido hasta ahora gran parte de la doctrina nacional, se detallarán soluciones al respecto de la punibilidad del cómplice interesado, ello sobre la base y el respeto de la imputación objetiva en el aumento de un peligro ya existente, el cual tiene que devenir de la conducta del traficante pero en participación necesaria del interesado en la creación del peligro, a fin de que se justifique y se legitime la activación del ius puniendi del Estado; no obstante, aun no aceptándose tal criterio (de creación de peligro compartido al bien jurídico protegido en el delito de tráfico de influencias por el mero hecho de que los tipos penales están dirigidos a los autores), con la clasificación que brindaré, respecto de los delitos de participación necesaria, bastará para entender que el cómplice interesado si es punible, ya que según la doctrina alemana en los delitos de participación necesaria impropia la regla de impunidad (del partícipe necesario) no es aplicable.

\section{EL DELITO DE TRÁFICO DE INFLUENCIAS. MARCO PRELIMINAR Y CONCEPTUAL}

Como bien detalla Salinas Siccha (2014):
El delito de tráfico de influencias o también conocido en la doctrina en su acepción romana, como "venta de humo" no estaba regulado en el texto original del Código Penal de 1924. Es recién con el Decreto Legislativo $\mathrm{N}^{\circ} 121$ del 12 de junio de 1982, que se tipifica por primera vez en nuestra patria. El decreto legislativo incorporó al Código Penal el artículo $353^{\circ}$-A cuyo contenido tipificó el delito de tráfico de influencias, el cual no estaba en el proyecto inicial del citado decreto legislativo, sino que fue introducido por funcionarios que redactaron el texto definitivo; por lo tanto, no se discutieron a fondo las razones para tipificarlo. Constituyó una expresión de la idea políticamente predominante de entonces, que apuntaba a facilitar la represión eficaz de los funcionarios que durante el fenecido gobierno militar habían cometido delitos contra los intereses del Estado. (Páginas 581-582)

Lo cual no pretende este breve artículo jurídico, puesto que, el autor no comparte las razones que justifican un derecho penal del enemigo, que más sienta sus bases en cuestiones de política-criminal simbólica, que poco a poco, van avasallando los criterios dogmáticos que son los que deberían de tenerse en cuenta para justificarse la sanción de una conducta de manera racional.

El Código Penal de 1991 tipificó en su artículo $400^{\circ}$ al delito de tráfico de influencias, no obstante, su contenido inicial fue objeto de diversas modificaciones (Salinas Siccha 2014).

- Por el artículo $1^{\circ}$ de la Ley $N^{\circ} 28355$ del 6 de octubre de 2004

- Luego fue modificado por la episódica y polémica Ley $\mathrm{N}^{\circ} 29703$ del 10 de junio de 2011, la misma que fue derogada en parte por la Ley $\mathrm{N}^{\circ} 29758$ del 21 de julio de 2011. Esta última ley volvió al texto impuesto por la Ley $\mathrm{N}^{\circ} 28355$.

- Finalmente, la última modificación introducida por la Ley $\mathrm{N}^{\circ} 30111$ del 26 de noviembre de 2013, precisa el contenido taxativo del tipo penal de tráfico de influencias previsto en el artículo $400^{\circ}$ del Código Penal, de la siguiente forma:

El que, invocando o teniendo influencias reales o simuladas, recibe, hace dar o 
prometer para sí o para un tercero, donativo o promesa o cualquier otra ventaja o beneficio con el ofrecimiento de interceder ante un funcionario o servidor público que ha de conocer, esté conociendo o haya conocido un caso judicial o administrativo, será reprimido con pena privativa de libertad no menor de cuatro ni mayor de seis años y con ciento ochenta a trescientos sesenta y cinco días-multa.

Si el agente es un funcionario o servidor público, será reprimido con pena privativa de libertad no menor de cuatro ni mayor de ocho años e inhabilitación conforme a los incisos 1 y 2 del artículo $36^{\circ}$ del Código Penal y con trescientos sesenta y cinco a setecientos treinta días-multa. (Salinas Siccha 2014, Páginas 582-583)

Para Núñez Pérez (2011) esta modalidad delictual ha sido considerada, siguiendo la posición doctrinaria más avanzada y moderna, como un delito de pacto sceleris, pues su existencia requiere de presencia de dos personas: un vendedor de humo (intermediario o traficante de influencias) y comprador de humo (interesado o beneficiario con la influencia).

Para Reátegui Sánchez (2015) este delito es una suerte de acto preparatorio elevado a la categoría de delito independiente del cohecho o del tráfico de influencias. Con este precepto, lo que el legislador quiere, es adelantar las barreras de protección penal, tratándose de un delito de peligro abstracto, de un delito mutilado en dos actos, que se caracteriza en que la intención del autor al ejecutar la acción típica debe dirigirse a realizar otra actividad posterior del mismo sujeto -delito de dos actos-.

La figura del "tráfico de influencias" se acerca al injusto típico del "cohecho" pero no es idéntico a este: con este tipo penal se busca abarcar penalmente la "compraventa" de la influencia que se tenga o pueda tener en funcionarios públicos; o sea, se adelantan las barreras del derecho penal para reprimir conductas que pudieran influir efectivamente en el ejercicio funcionarial (Reátegui Sánchez 2015).

Con ello lo que quiere señalar la doctrina $-y$ lo hace de manera precisa-, es que lo que se busca sancionar son posibles conductas que de no existir el tipo penal de tráfico de influencias serían conductas impunes, en otras palabras, se está sancionado un acto preparatorio al delito de cohecho, y ello, porque el delito de tráfico de influencias se caracteriza por ser un "delito de intermediación", esto es, que para que el interesado pueda llegar hacia el funcionario o servidor público que esté conociendo o haya conocido un caso judicial o administrativo requiere precisamente de la intermediación del vendedor de humo, ergo, si en el plano fáctico no se encuentra el traficante de influencias, es decir, si el interesado acude directamente ante el funcionario o servidor público mediante un medio corruptor, el funcionario respondería por cohecho pasivo y el interesado respondería por el delito de cohecho activo.

Teniendo en cuenta ello pasaremos a analizar la tipicidad objetiva de este tipo penal, y ello, a fin de poder sentar las bases de lo que vienen a configurar las diversas modalidades en que se puede configurar un delito de tráfico de influencias, dado su carácter de delito complejo al regular verbos rectores y verbos complementarios que tienen que darse necesariamente para recién entender que estamos ante una conducta típica del delito de tráfico de influencias, y así posteriormente verificar porqué estamos ante una conducta de pacto sceleris que requiere la participación necesaria del cómplice interesado.

\section{Tipicidad objetiva}

\section{Sujeto activo}

El artículo $400^{\circ}$ de nuestro Código sustantivo, en el primer párrafo, establece que cualquier persona puede realizar la conducta, por lo tanto, se trata de un sujeto activo indeterminado. En efecto, al cometerse en el ámbito privado, los sujetos del tráfico de influencias (traficante e interesado) siempre actúan desempeñando el rol básico de ciudadano, de modo que no ostentan un deber positivo de fomentar la correcta administración pública, sino que únicamente infringen el deber de abstenerse de lesionar la credibilidad que de la sociedad tiene al menos a nivel normativo en la imparcialidad y objetividad de la administración (Reátegui 2015).

Estamos pues ante un delito de dominio, y, por tanto, el sujeto activo si es imputable a título de autor debe tener el dominio del 
Dogmatic reasons that justify and solve the controversy on the punibility of the "complice" interested in the crime of traffic of influences

hecho per se, si alguien es participe debe pues contribuir en la realización del hecho delictivo en respeto de las reglas generales de la autoría y participación (será participe por ejemplo -en el caso precisado en la introducción-quien haya facilitado el número del postulante al Juez Superior para que éste venda sus influencias reales), mas el problema planteado en este artículo, no versa sobre tales casos de complicidad, sino más bien, en el hecho de determinar si el interesado (que es el comprador de influencias) puede responder penalmente como cómplice, o si más bien por ser un partícipe necesario debe ser impune.

\section{Sujeto pasivo}

El sujeto pasivo solo es el Estado como único titular del bien jurídico, y ello es importante tenerlo en cuenta para las conclusiones y soluciones que brindará este trabajo, puesto que, la doctrina nacional que se opone a la punibilidad del cómplice interesado no se ha percatado que en el delito de tráfico de influencias el interesado no es víctima del delito ni mucho menos titular del bien jurídico protegido, argumento fundamental para negar la impunidad de éste, distinto a lo que sucede en los delitos de estafa o usura en donde el sujeto pasivo requiere intervenir necesariamente, empero, en estos casos el afectado si es víctima del delito.

\section{Conducta tipica}

Existen diversas modalidades en que podría configurarse un delito de tráfico de influencias (y ello se evidencia de la sola lectura del artículo $400^{\circ}$ del Código Penal), para mayor precisión, se realizará un análisis disgregado de estas:

\section{Las influencias invocadas o simuladas pueden ser reales o simuladas}

El primer elemento objetivo que el operador jurídico debe verificar es si el sujeto activo ante un tercero interesado, ha invocado, citado, alegado o aducido tener influencias al interior de la administración de justicia para lograr que sus funcionarios o servidores públicos se pronuncien en un sentido determinado en los procesos judiciales o administrativos. (Salinas Siccha 2014, Página 587).

Es sencillo inferir, que las influencias reales que se tienen, se dan en el supuesto en que el agente no aduce o alega tener influencia, esto es, que el tercero interesado la deduce por el cargo que desempeña el vendedor de influencias, sostengo pues, que ello en la práctica, en generalidad (no en su totalidad de supuestos), se evidencia, cuando el vendedor de influencias es un funcionario o servidor público; entiendo pues, que es en estos casos, es decir, "en la tenencia de influencias" y no en la "invocación" de influencias en donde es factible la instigación del interesado; y preciso ello, porque el Acuerdo Plenario $\mathrm{N}^{\circ}$ 03-2015 no precisa en que modalidad conductual del tráfico de influencias es factible que sea punible conducta del instigador interesado, sin embargo, la conducta punible del cómplice interesado si es factible en ambos supuestos.

Se tiene influencias simuladas cuando estas son invocadas por el vendedor de influencias pero en realidad no existen. ${ }^{3}$

En síntesis, el agente cita o aduce tener, o tiene objetivamente influencias con la finalidad de que el tercero interesado le entregue o le realice la promesa de entregarle un donativo o cualquier otra ventaja o beneficio a cambio. Es irrelevante penalmente si la influencia que invoca el sujeto activo es real o simulada, pues en ambos casos se evidencia la conducta típica, no obstante, considero que el tráfico de influencias en su modalidad simulada ya se encuentra sancionada en el tipo penal de estafa.

Empero, para efectos de entendimiento, es de resaltar que estaremos ante una influencia real cuando se verifique que el agente realmente tiene contacto con los funcionarios o servidores públicos de la administración de la justicia, y, por tanto, tiene poder o capacidad de orientar su voluntad hacia una dirección determinada.

$\mathrm{Y}$ estaremos ante influencias simuladas o venta de humo cuando se verifica que el agente no tiene contacto con los

\footnotetext{
3 Es por ello que en la doctrina se discute si en realidad estamos ante el delito de estafa y no de tráfico de influencias, a propósito y con más profundidad revisese el articulo jurídico del profesor sanmarquino GALVAN RAMOS, Marcos Iván. ¿El tráfico de influencias como modalidad del delito de estafa?: El contenido del engaño como única diferencia entre el artículo $196^{\circ}$ y la forma simulada del artículo $400^{\circ}$ del Código Penal.
} 
funcionarios o servidores públicos de la administración de la justicia $\mathrm{y}$, por lo tanto, no hay forma ni tiene capacidad de orientar su voluntad a una dirección determinada (Salinas Siccha 2014).

La doctrina peruana es unánime al considerar que esta modalidad no posee entidad lesiva para el bien jurídico que se pretende proteger, debiéndose optar por la descriminalización, al no configurarse las exigencias de antijuricidad material (San Martín Castro 2002), criterio de descriminalización que el autor comparte en la modalidad de tráfico de influencias simuladas, por entenderse, que esta conducta ya se encuentra regulada en el delito de estafa; empero, esta problemática no será discutida en este artículo, porque de analizarse todos los problemas de este tipo penal, se requeriría un libro, y no artículo como es lo que se me ha encomendado.

Como podemos verificar, las problemáticas sobre el delito de tráfico de influencias son diversas, entre ellas como hemos detallado tangencialmente el caso del tráfico de influencias simulado, en el cual, al no ponerse siquiera en peligro abstracto el correcto funcionamiento de la Administración Pública que es lo que protege este tipo penal, debería ser entendido como un delito de estafa y no como un delito contra la Administración Pública; máxime si se cumplen 04 presupuestos este tipo delictivo: Engaño en la influencias inexistentes; error en el interesado que cree en la supuesta influencia del vendedor; acto de disposición patrimonial a través del medio corruptor, perjuicio económico.

\section{Recibir, hacer dar o prometer}

El recibir significa que el agente acepta, acoge, admite, embolsa o toma el donativo $\mathrm{u}$ otra ventaja o beneficio que el tercero interesado le entrega a cambio de las influencias que ofrece aquel. El tercero interesado ya está predispuesto a hacer la entrega a cambio de la promesa de influenciar (Salinas Siccha 2014).

Mediante el uso del verbo recibir, el legislador ha pensado, en primer lugar, que la iniciativa proviene generalmente del tercero que da la ventaja. Mediante el acto de entregar en caso de no existir pedido de parte de quien recibe el que da empuje al agente a aceptar y recibir la ventaja, ocasión en que este último ofrece interceder para hacer lo que le pide el tercero ${ }^{4}$, en esta conducta podría darse pues, la figura del instigador interesado en el delito de tráfico de influencias, que como ya he detallado en la introducción, conforme al Acuerdo Plenario $\mathrm{N}^{\circ}$ 03-2015 si es punible, por lo que tampoco será materia de análisis en el presente artículo al haberse solucionado este problema con tal decisión de la Corte Suprema.

El hacer dar significa que el agente logra o convence al tercero interesado que le entregue, ceda, conceda, facilite o provea del donativo u otra ventaja. Hacer dar se traduce en el hecho que el agente traficante, invocando tener influencias, logra que el tercero interesado le dé o facilite un donativo $\mathrm{u}$ otra ventaja o beneficio. El agente no se limita a recibir, sino a hacer nacer en el tercero interesado la voluntad de entregar el donativo $\mathrm{u}$ otro beneficio a cambio de las influencias que oferta el traficante (Salinas Siccha 2014), esta conducta pues, evidencia que el agente debe realizar una conducta activa con la finalidad de que el comprador de influencias en efecto acepte tal venta de humo.

El prometer significa que el agente invocando tener influencias logra que el tercero interesado le ofrezca, proponga, pacte o prometa la entrega de un beneficio patrimonial o de cualquier otra índole en un futuro cercano. Mayormente aparece cuando el agente logra que el tercero interesado le ofrezca entregar donativo una vez que el funcionario o servidor de la administración de justicia se pronuncie en un determinado sentido (Salinas Siccha 2014).

Medios corruptores: donativo, promesa, cualquier otra ventaja o beneficio

El donativo es aquel bien dado o prometido a cambio de la influencia efectuada por el agente. Es pues la contraprestación por la venta de influencias aceptada por el comprador de influencias.

\footnotetext{
4 Exp. N 5002-97-Lima, Sala B.
} 
Dogmatic reasons that justify and solve the controversy on the punibility of the "complice"

interested in the crime of traffic of influences

Donativo, dádiva o presente son sinónimos, expresan una misma idea: obsequio o regalo. La calidad del donativo penalmente relevante tiene que ver con su poder objetivo para motivar la voluntad y los actos del agente hacia una conducta deseada y de provecho para el que otorga o promete otro funcionario o particular. Se entiende que el donativo desde poseer una naturaleza material, corpórea y tener valor económico: bienes muebles, inmuebles, dinero, obras de arte, libro, etc.

La promesa, en cambio, se traduce en un ofrecimiento hecho al agente de efectuar la entrega de donativo o ventaja debidamente identificada o precisa en un futuro mediato o inmediato. Se exige que la promesa tenga las características de seriedad y sea posible material y jurídicamente. El cumplimiento de la promesa resulta irrelevante para la configuración de delito. El delito se consuma con la verificación de la simple promesa.

El contenido de la promesa puede ser muy variado: la entrega futura de una oferta remunerativa, bien mueble o inmueble, ventajas (utilidades económicas, ascensos laborales, viajes, etc.) La modalidad de la promesa tiene que ser directa. El momento de hacerse realidad la promesa puede ser en un futuro cercano o mediato, incluso antes de que el funcionario o servidor influenciado se pronuncie de acuerdo con lo que el tercero o servidor pretende. Lo fundamental es el vínculo que une a los actos del traficante con la promesa efectuada.

Cualquier otra ventaja o beneficio debe entenderse como un mecanismo subsidiario y complementario, que cubre todo lo que no sea susceptible de ser considerado donativo. En una clausula general que completa la lista de ventajas enumeradas en el tipo penal donativo, promesa. Comprende a cualquier privilegio o beneficio que solicita o acepta el agente con la finalidad supuesta de influenciar ante un funcionario o servidor jurisdiccional o administrativo: empleos, colocación en áreas específicas, ascensos, premios, cátedra universitaria, viajes, becas, descuentos no usuales, favores sexuales, favores laborales, etc.
En suma, la expresión "cualquier otro beneficio o ventaja" comprende cualquier beneficio patrimonial como no patrimonial, pero que implique una utilidad apropiada para que el agente convenga en recibirla o aceptarla como objeto de la promesa de parte del tercero interesado (Salinas Siccha 2014).

\section{Ofrecimiento de interceder ante funcionario o servidor público}

Este elemento lo tiene claro la jurisprudencia en la calificación de la conducta punible, como se evidencia en la ejecutoria suprema del 22 de agosto de 2000. En efecto, allí se argumenta que

la negativa del encausado resulta un ineficaz intento por evadir la responsabilidad que le corresponde en cuanto al ilícito denunciado, habiéndose recibido además la declaración testimonial donde se detalla con precisión las circunstancias y modo en que actuó este procesado, tomando él la iniciativa de abordarla y ofrecerle su mediación en el trámite del proceso judicial en el que era parte, siempre que efectuara el pago del dinero en efectivo. $\left(\operatorname{Exp} \mathrm{N}^{\circ} 179-2000 \text {-Lima }\right)^{5}$

Funcionario o servidor que ha de conocer, esté conociendo o haya conocido un caso judicial o administrativo

El destino de las influencias que invoca o alega el traficante no es cualquier funcionario o servidor de la administración pública, sino solo un funcionario o servidor público que ejerce funciones al interior de la administración de justicia en el ámbito jurisdiccional o administrativo; ergo, otro vacío de este tipo penal se halla en el hecho de que las influencias vendidas que se castigan, no podrían darse en fuero distinto al jurisdiccional y administrativo, y si ello es así, en respeto del principio de legalidad habría que entender que si una persona vende sus influencias a otro quien compra, a través de una contraprestación (medio corruptor) con el ofrecimiento de interceder ante un caso fiscal, prima

5 En el mismo sentido la Sentencia de la Tercera Sala Penal Corporativa para Procesos Ordinarios con Reos Libres de la Corte Superior de Lima del 19 de diciembre de 1999, recaída en el Expediente $N^{\circ} 472-99$. 
facie estaríamos ante una conducta atípica de tráfico de influencias, empero, sin necesidad de que este problema se resuelva con modificaciones a la ley, ello tiene una solución interpretativa, que lamentablemente, no podrá ser trabajado en el presente artículo, porque este se encuentra dirigido a brindar soluciones dogmáticas respecto del cómplice interesado.

En otras palabras, conforme detalla Salinas Siccha (2014), no puede tratarse de un ofrecimiento de interceder ante cualquier funcionario de la administración de justicia, si no sobre aquel que ha de conocer, esté conociendo o haya conocido un proceso judicial o administrativo que interesa al tercero ante el cual el sujeto judicial o administrativo que interesa al tercero ante el cual el sujeto activo invoca o afirma tener influencias. Si se verifica que el destino de las influencias es un funcionario o servidor público que no tiene alguna relación funcional con el caso o proceso que interesa al tercero, el delito en hermenéutica jurídica no se verifica.

En resumen, teniendo en cuenta la tipicidad objetiva (ya desarrollada $u t$ supra) y subjetiva de Este tipo penal de tráfico de influencias (que es el dolo directo), pasaremos a precisar, el meollo esencial de la presente labor, la cual consiste en justificar las razones dogmáticas por las cuales el cómplice interesado debe responder penalmente, no obstante, previamente realizar una crítica al Acuerdo Plenario $\mathrm{N}^{\circ}$ 03-2015, que dio a entender, que el problema se había solucionado señalando que incluso que el cómplice interesado debería responder como instigador interesado; cuando ello, sobre la base de la dogmática penal es un absurdo jurídico.

Posterior a tal crítica, se precisará por qué el tipo penal de tráfico de influencias es un delito de participación necesaria impropiamonosubjetivo y un delito de encuentro, cuestiones dogmáticas, que brindarán la solución a esta prolongada controversia jurisprudencial y doctrinal.

Finalmente, se detallarán las posturas más relevantes de la doctrina nacional, respecto de argumentos a favor y en contra de la punibilidad del cómplice interesado; y así poder concluir con claridad, las razones dogmáticas que justifican y solucionan este problema que no fue solucionado por el Acuerdo Plenario $\mathrm{N}^{\circ}$ 03-2015 (en el supuesto del cómplice interesado).

\section{LA CONTRARIA CONCEPCIÓN DOGMÁTICA DE LA CORTE SUPREMA EN EL ACUERDO PLENARIO ${ }^{\circ}$ 03- 2015 RESPECTO DE LA PUNIBILIDAD DEL INTERESADO EN EL DELITO DE TRÁFICO DE INFLUENCIAS}

El 21 de junio de 2016 se publicaron en el diario oficial El Peruano los Acuerdos Plenarios que se habían adoptado en el IX Pleno Jurisdiccional de las Salas Penales de la Corte Suprema, siendo uno de los temas relevantes para este artículo, lo resuelto respecto a la punibilidad del interesado en el delito de tráfico de influencias.

Las Salas Supremas Penales Permanente y Transitoria, en referencia al título de imputación correspondiente al interesado en la compra-venta de influencias, establecieron como fundamento, que, en ningún caso, dicho interesado puede ser considerado como cómplice (primario o secundario) en el delito de tráfico de influencias, cuestión que contraviene lo planteado por este artículo; así pues, lo detalla el fundamento jurídico $\mathrm{N}^{\circ} 09$ que se cita a continuación:

9. En este sentido, el tercero interesado en el delito de tráfico de influencias, mejor dicho, quien promete o entrega el donativo, la ventaja o el beneficio al autor, no puede ser considerado cómplice de tal ilícito [así lo entiende también la Ejecutoria Suprema de 24 de febrero de 2014 (RN No 1692 2013)]. En sentido estricto, el "comprador o solicitante de influencias" no presta ningún tipo de colaboración en la comisión del delito $-\mathrm{O}$, más concretamente, en la acción típica prevista por el tipo penal-, en la medida que él es partícipe necesario de un delito de encuentro, su colaboración "necesaria", o enmarcada dentro del rol típico, resultaría impune desde la perspectiva de la complicidad [Abanto Vásquez, Manuel: Los Delitos contra la administración pública en el Código penal peruano, Lima, 2001, p. 472]. Aun cuando la intervención del tercero interesado en la 
Dogmatic reasons that justify and solve the controversy on the punibility of the "complice" interested in the crime of traffic of influences

fenomenología delictiva es indispensable para el hecho globalmente entendido como el comercio ilícito de influencias, resulta claro que su intervención no es propiamente de contribuir a la configuración de los elementos típicos centrales del delito de tráfico de influencias, tales como recibir o solicitar una ventaja indebida tras atribuirse la existencia de dichas influencias. (Acuerdo Plenario $\mathrm{N}^{\circ}$ 03-2015, Fundamento 9)

La Corte Suprema precisó pues, que la única forma en que podría responder el interesado en el delito de tráfico de influencias es a título de "instigador", y así lo detalla en el fundamento jurídico $\mathrm{N}^{\circ} 11$ del Acuerdo Plenario en mención:

En síntesis, el "comprador solicitante de influencias", es decir, "el interesado" en el delito de tráfico de influencias, solo podrá ser considerado instigador siempre y cuando sus actos en fase previa a la ejecución hayan creado o reforzado la resolución criminal en el "vendedor de influencias" mediante un influjo psíquico. Naturalmente, en el caso concreto deberá probarse que efectivamente el interesado hizo surgir la resolución criminal del traficante de influencias o reforzó la resolución criminal preconcebida. Por tanto, si la solicitud de influencias del interesado no generó ni fortaleció la resolución criminal del autor, la conducta de aquel deviene en impune, en la medida que el tipo penal no abarca a otra forma de participación para dicho interviniente. (Acuerdo Plenario $\mathrm{N}^{\circ}$ 032015, Fundamento 11)

En resumida cuenta, los criterios jurisprudenciales por los cuales se precisan que el interesado solo podría responder como instigador, y que fluyen de una interpretación de los fundamentos jurídicos $7,8,9,10$ y 11 del Acuerdo Plenario $\mathrm{N}^{\circ}$ 03-2015, son los siguientes:

El principio de accesoriedad, como concreción del concepto restrictivo de autor, implica que el participe ocupe un lugar accesorio respecto del autor, siendo necesario para la punibilidad de aquel, según doctrina mayoritaria, entre otros elementos, que el hecho delictivo cometido por el autor sea típico y antijurídico (accesoriedad limitada).
El partícipe desarrolla un papel facilitador de la ejecución del delito y no el rol de dueño y señor del hecho.

A criterio personal, considero que la Corte Suprema se equivoca al postular como premisas argumentativas el hecho de que el participe no tiene el dominio del hecho, puesto que ello es evidente en respeto de lo que establece la visión bipartita de la intervención delictiva (autoría y participación).

Además, la Corte Suprema no precisa con claridad porque se afecta la accesoriedad limitada, y ello tiene su razón de ser, en que se ha venido tratando al delito de tráfico de influencias como un delito de participación necesaria propio (en donde el cooperador necesario es impune), $\mathrm{y}$, entendido también como un delito plurisubjetivo, concepción errónea que ya se precisará en el capítulo correspondiente de este artículo, en donde se detallarán, las razones por las cuales el delito de tráfico de influencias conforme está configurado en nuestro Código Penal, es un delito mono subjetivo de participación necesaria impropia y de encuentro, es decir, en donde el partícipe necesario no es impune, contrario a lo que ocurre en los delitos de participación necesaria propia (Ejemplo: delito de estafa y usura); y, en donde, el interesado no se haya tipificado en el tipo penal (contrario a lo que sucede en los delitos plurisubjetivos, ejemplo de ello en nuestra normativa nacional es el delito de cohecho pasivo y activo siendo este último el que precisamente regula taxativamente la conducta del interesado).

El cómplice es quien realiza un aporte material (o psicológico) orientado siempre a auxiliar al autor en la realización del tipo penal.

En este criterio jurisprudencial recaído en el fundamento jurídico de $\mathrm{N}^{\circ} 8$ del Acuerdo Plenario $\mathrm{N}^{\circ}$ 03-2015, evidencia un criterio claramente contrario a lo que debe entenderse como cómplice, confundiéndolo incluso con la conducta de un instigador, al precisarse que el cómplice realiza aportes psicológicos orientados al auxilio a la realización del tipo penal, cuando ello es incorrecto, si se entiende que la única determinación psicológica punible, como forma de intervención delictiva, es la instigación.

El comprador o solicitante de influencias nunca podrá ser considerado cómplice según 
los alcances del artículo 25 del CP, como la persona que auxilia o colabora dolosamente en la realización del tipo penal, pues para ello tendría que ayudar al vendedor de influencias en la realización del verbo rector, esto es, en la invocación de influencias, lo cual, es imposible. El tercero interesado, esto es, quien promete o entrega el donativo, la ventaja o el beneficio al autor no puede ser considerado cómplice de tráfico de influencias.

Este análisis de la Corte Suprema, da cuenta, de que se está teniendo en cuenta la teoría de accesoriedad limitada, esto es, sobre la base de la dependencia del injusto de participación al injusto de autoría, el cual versa en que se castiga al partícipe (y se entiende como tal) sobre la base del injusto penal realizado por el autor del delito, empero esta concepción considero no acorde al funcionalismo contemporáneo, además de contravenir el principio de responsabilidad personal.

La afectación de este principio constitucional de responsabilidad personal en la dependencia del injusto del participe con el injusto del autor, es claramente ejemplificada por el profesor Reaño Peschiera (2004), quien señala que: la doctrina dominante defiende la tesis de la dependencia (accesoriedad) del injusto de participación al injusto de autoría, afirmando que la razón por la que se castiga al participe reside en haber co-causado el hecho principal, sea determinando al autor para que lo realice (instigación) o favoreciendo al autor su realización (complicidad). Nótese que para esta concepción la relación entre el suceso principal y los partícipes se encuentra mediatizada por el autor, de modo que el partícipe solo accede indirectamente al tipo de la Parte Especial. La accesoriedad constituye - para esta tesis- la esencia de la participación, de modo que la punición del partícipe depende necesariamente del hecho del autor; empero tal posición contraviene el principio de responsabilidad personal al hacer depender el injusto del participe al injusto del autor. ${ }^{6}$

Para ello sostiene el autor citado, que: Para compatibilizar accesoriedad y

6 Esta solución, de modo inverso a lo que ocurre con la tesis de la autonomía (no accesoriedad) de la participación, respeta el principio del hecho al dejar impune un suceso que no comporta perturbación social, pero vulnera seriamente el no comporta perturbacion social, pero vulnera seriamente el
principio de responsabilidad personal al hacer depender el injusto personal del participe al injusto realizado por otra persona. autorresponsabilidad debe desterrarse la idea de que el partícipe contribuye a realizar un hecho ajeno, exclusivo del autor, pues el suceso lesivo pertenece a todos los intervinientes punibles, aunque en distinto grado de intensidad. Los aportes al evento delictivo no deben considerarse de modo aislado, como si cada sujeto realizara un injusto (hecho antijurídico) por separado, sino que deben valorarse conforme a una perspectiva global, que considera la existencia de un solo injusto al que aceden directamente todos los intervinientes. Por ello, debe hablarse de injusto de intervención y no distinguir entre injusto de autoría e injusto de participación. Por su parte, la accesoriedad debe entenderse como nexo que vincula directamente a los intervinientes con el injusto, de modo que cada uno accede al hecho principal en función a su propio aporte.

$\mathrm{Si}$ bien la intervención del tercero interesado en la fenomenología delictiva es indispensable para el hecho globalmente entendido como el comercio ilícito de influencias, resulta claro que su intervención no es propiamente la de contribuir a la configuración de los elementos típicos centrales del delito, tales como recibir o solicitar una ventaja indebida tras atribuirse la existencia de influencias. (Reaño Peschiera 2004, Página 105)

La Corte Suprema en este criterio establecido en el fundamento jurídico $\mathrm{N}^{\circ} 9$, resalta que el delito de tráfico de influencias es un delito de participación necesaria, y por ello, concluye que sería imposible analizarlo bajo las reglas generales de la complicidad, empero, tal conclusión de la Corte Suprema es incorrecta, porque el Código Penal peruano no establece reglas específicas de cómo debe interpretarse la intervención delictiva en este tipo de casos en donde existe un colaborador necesario.

Ergo, entendiendo a la accesoriedad bajo el injusto de la intervención, esto es, no limitando la conducta propia del participe con la del autor, sino más bien armonizando el concepto de que ambos contribuyen al hecho delictivo en la creación del peligro al bien jurídico (conforme criterios de imputación objetiva), es factible que el cómplice interesado responda penalmente, máxime, si éste con su conducta, es indispensable para la realización del hecho 
Dogmatic reasons that justify and solve the controversy on the punibility of the "cómplice" interested in the crime of traffic of influences

delictivo, y además, no es objeto de protección de la norma (es decir, no es titular del bien jurídico protegido).

No obstante, aun no asumiéndose la doctrina contemporánea del injusto de la intervención, esto es, respetando la accesoriedad dependiente del participe con el autor(injusto de participación dependiente del injusto de autoría), se llega a la misma conclusión de que el cómplice interesado debe responder penalmente, puesto que, en el no concurren las razones ontológicas por las cuales el partícipe necesario es impune, -(1) El interesado no es víctima del delito (2) El interesado no se encuentra sometido a la acción típica del vendedor de influencias-, sino más bien, tiene pretensiones sobre tal comercio ilícito de influencias, por ello, debe comprenderse que el delito de tráfico de influencias es un delito de participación necesaria impropia como denomina la doctrina alemana a este tipo de delitos, en los cuales, si cabe la punibilidad del cómplice necesario; estas razones, serán profundizadas en el acápite correspondiente.

- La instigación consiste en hacer surgir en otro la resolución criminal, o en determinar a otro, mediante influjo psíquico, a la comisión de un delito. Se erige en la condición sin la cual el evento delictivo no habría tenido lugar. De no existir el influjo psíquico del instigador, el ilícito no se cometería. A la conducta del instigador debe ser posible imputarle objetivamente la determinación dolosa del instigado a cometer el delito.

- La actuación del tercero interesado se erige claramente en una instigación. La conducta típica del autor responde única y sustancialmente al influjo psíquico del tercero interesado, quien lo determina dolosamente a llevar a cabo el hecho principal consistente en ofertar las influencias con el fin de favorecerlo. Es el acto de determinación del tercero interesado el que activa el comercio ilícito de influencias o el que, en cualquier caso, permite o refuerza su efectiva continuación. El impulso psicológico del tercero interesado no constituye cualquier tipo de aporte para posibilitar el delito, sino que está orientado exclusivamente a la compra de influencias del autor del delito, resulta así ciertamente determinante para su concreción.
- El comprador solicitante de influencias o interesado, será instigador cuando no encontrándose el instigador propenso o proclive a actos de corrupción, lo haya convencido a cometer delito. No obstante, aun en el supuesto en el que el autor esté ya decidido a vender las influencias al comprador solicitante de influencias, pudiendo parecer mínima la aportación de este último, inclusive en este caso él es instigador, pues habrá reforzado la resolución criminal del autor. En ambos casos, para que el interesado sea considerado instigador debe haber realizado actos en fase previa a la ejecución del delito, que hayan creado o reforzado la resolución criminal en el vendedor de influencias mediante un influjo psíquico, debiendo ello acreditarse probatoriamente.

Concluye la Corte Suprema (sobre el análisis de la punibilidad del interesado), arguyendo que es posible la instigación en la conducta de éste, si y solo si, se de en la fase previa al inicio de la ejecución del delito, es decir previo, a la tentativa del tráfico de influencias, sin embargo, no detalla en que modalidad de las tantas del tráfico de influencias podría darse tal instigación, ni mucho menos cuando cabría la tentativa en este delito de peligro abstracto.

Considero, de que solo es posible esta forma de intervención delictiva-instigación-en el tercero interesado (comprador de influencias), cuando el vendedor de influencias solo tiene estas influencias reales, mas no cuando las invoca, porque de ser así, ya no existiría instigación alguna, en el entendimiento, de que la idea criminal ya se encontraba en la concepción psicológica del vendedor de influencias.

Conforme a las críticas planteadas, considero que la Corte Suprema en este Acuerdo Plenario $\mathrm{N}^{\circ}$ 03-2015, no ha profundizado en las razones para negar de plano la posibilidad de la existencia de un "cómplice" interesado (comprador de influencias) en este tipo delictivo de tráfico de influencias.

Para propósito de brindar una solución correcta sobre la cuestión de la punibilidad del cómplice interesado, a continuación, se precisa porque este delito de tráfico de influencias al ser un delito de participación necesaria impropia, monosubjetivo y de encuentro (en donde no es 
víctima del delito y coadyuva a la creación del peligro abstracto a la administración pública), merece en su análisis, la posibilidad de la punibilidad del cómplice interesado.

\section{EL DELITO DE TRÁFICO DE INFLUENCIAS ES UN DELITO DE PARTICIPACIÓN NECESARIA, UN DELITO MONOSUBJETIVO Y UN DELITO DE ENCUENTRO}

\section{E1 delito de tráfico de influencias como un delito de participación necesaria impropio-mono subjetivo $y$ de encuentro}

Existen algunos delitos en el Código penal que están configurados de tal forma que para su realización requieren necesariamente la intervención de varios sujetos sin que, a diferencia de lo que ocurre con las restantes figuras delictivas, sea posible cometer el hecho delictivo aisladamente por un solo individuo (Carrasco 2002).

Precisa la profesora española Carrasco Andrino (2002) que: para referirse a los casos en los que junto a una pluralidad de conductas se requiere estructuralmente una pluralidad de sujetos se habla, entre la doctrina alemana, de participación necesaria o impropia (notwendige Teilnahme). Con esta denominación se destaca su carácter de excepción frente a las reglas generales de participación, en las que la intervención de una pluralidad de sujetos es, en cambio, de índole ocasional o eventual. Los autores italianos, por su parte, aunque también se sirven de la expresión concurso necesario, suelen referirse a tales supuestos con la expresión delitos plurisubjetivos o pluripersonales (reato plurissoggettivo). Se llama, así, la atención sobre su peculiar estructura típica. De manera que parece que con esta diferente nomenclatura se busca evidenciar una distinta perspectiva de estudio que, en el caso de la doctrina alemana, lleva a concentrar los esfuerzos en el examen de sus consecuencias jurídicas; a saber, en el examen de las relaciones que guardan participación necesaria con las reglas generales de autoría y de participación. En el caso de la doctrina italiana, conduce a una mayor preocupación por su concepto, ubicando el estudio de esta problemática ya en sede de tipicidad.
En efecto, al parecer existe cierta confusión respecto del enfoque terminológico distinto otorgado a los delitos de participación necesaria y a los delitos plurisubjetivos, puesto que, no se determina si poseen el mismo contenido jurídico o si por el contrario poseen sus características y contenidos propios; o más aún, si estamos ante clasificaciones que pueden conjugarse en aras de brindar a la dogmática, soluciones de interpretación para este tipo de delitos, en los que, la intervención de una pluralidad de sujetos (2 o más) es necesaria para su realización.

Una correcta distinción entre los delitos plurisubjetivos y los delitos de participación necesaria, (dada esta aparente confusión en contenido y terminología de los delitos plurisubjetivos y de participación necesaria) es la que detallan con mucha lucidez: Vives Anton y Cobo del Rosal (Citados por Carrasco 2002), quienes precisan que la expresión participación necesaria hace referencia a aquellos tipos penales cuya realización exige la concurrencia de varias acciones de diferentes personas, mientras que el concepto de delito plurisubjetivo queda reservado para aquellos otros en los que la pluralidad de personas se traduce en una pluralidad de sujetos activos, a diferencia de que en los delitos plurisubjetivos la pluralidad de agentes o sujetos activos del hecho deben estar tipificado taxativamente.

A partir de esta diferenciación, se ha deducido una relación de género a especie entre ambas categorías, estimándose que los delitos pluripersonales representan una especie dentro del género común de los delitos de participación necesaria (Carrasco 2002); cuestión que es fundamental para entender la clasificación que este humilde autor otorgará en este artículo jurídico respecto de los delitos de participación necesaria.

- GÉNERO: Delitos de participación necesaria.

- ESPECIE: Delitos plurisubjetivos.

En síntesis a lo acotado hasta acá, la realidad, es que existe una diferencia sustancial que no es solo terminológica en los delitos de participación necesaria y los delitos plurisubjetivos, ello radica pues, en los distintos enfoques de estudio que le otorgue el sistema jurídico-penal de cada Estado, ya que, conforme a lo precisado por la doctrina italiana se otorga 
Dogmatic reasons that justify and solve the controversy on the punibility of the "cómplice" interested in the crime of traffic of influences

un enfoque dogmático desde el análisis de la tipicidad de la conducta (que supedita tal denominación de delito plurisubjetivo a su regulación legal), sin embargo, la doctrina alemana entiende al problema, desde su ámbito de la consecuencia jurídica (punibilidad) a aplicarse por la intervención plural en el hecho delictivo (autoría y participación); no obstante, a fin de zanjar tal diferencia en el examen de esta cuestión dogmática, y mas bien armonizar los conceptos que nos van a permitir entender porque la conducta del cómplice interesado en el delito de tráfico de influencias es punible, se propugna la siguiente solución -en base a una clasificación de los delitos de participación necesaria-, que se servirá tanto de la doctrina italiana como de la alemana para ello:

Hay que tener en cuenta prima facie, dos tipos de clasificaciones en los delitos de participación necesaria, las cuales propongo, y pretendo, que puedan armonizar y ayudar a la interpretación correcta del tipo penal de tráfico de influencias, y a todo delito de participación necesaria:

\section{Clasificación por la pluralidad de participes necesarios previstos en el tipo penal}

Se conocen como:

1. Delitos de participación necesariaplurisubjetivos: Acá se hallan los delitos que requieren para su realización la participación de dos o más personas, empero, esta participación debe estar regulada taxativamente en el tipo penal; para ejemplo claro de nuestra normativa tenemos el caso del "cohecho". Respecto de esta clasificación, no hay problema en entender que los que intervienen en el hecho delictivo pueden ser autores o coautores, precisamente porque la propia tipificación del delito así lo prevé.

2. Delitos de participación necesaria-mono subjetivos: En este grupo se hallan los delitos que requieren para su realización la participación de dos o más personas, empero, esta participación no debe estar regulada taxativamente en el tipo penal, para ejemplos tenemos pues: al tipo penal de estafa, usura, tráfico de influencias, etc. De esta clasificación, a diferencia de la anterior, surgen problemas para entender si es que el partícipe necesario es punible o no, precisamente porque el tipo penal no prevé taxativamente su conducta, y además, porque se entiende como regla general, que los partícipes necesarios son impunes (siendo entendidos como objetos de protección del delito o incluso como víctimas del delito tal como sucede en los delitos de estafa o usura, mas no con el delito de tráfico de influencias en donde la víctima no es el interesado, y en donde el bien jurídico genérico protegido es el Correcto Funcionamiento de la Administración Pública).

\section{Clasificación por la punibilidad del participe necesario}

1. Delitos de participación necesaria-propios: Son aquellos delitos en los cuales se requiere la participación necesaria de dos o más personas para la realización del hecho delictivo; empero, en este tipo de delitos el partícipe necesario es víctima del delito, por lo que no corresponde su punibilidad, a excepción de que realice conductas que desborden el tipo delictivo del cual fue víctima.

2. Delitos de participación necesaria-impropios: Son aquellos delitos en los cuales se requiere la participación necesaria de dos o más personas para la realización del hecho delictivo; empero, en este tipo de delitos el partícipe necesario no es víctima del delito, por lo que su conducta si es punible, máxime si contribuye con su realización a la creación del peligro para el bien jurídico.

Con esta clasificación, sostengo que queda zanjada esta aparente confusión terminológica, que ha permitido que nuestra doctrina nacional venga confundiéndose al denominar al delito de tráfico de influencias como un delito plurisubjetivo $^{7}$, cuando en realidad, si bien estamos ante un delito en el que intervienen varios sujetos, empero, tal denominación de plurisubjetivo es incorrecta, si tenemos en cuenta, que la génesis italiana de tal denominación, tiene su razón de ser en la

7 Este error de concepción ha sido repetido desde autores renombrados como el maestro HURTADO POZO (En: HURTADO POZO, José. Interpretación y Aplicación del art. 400 CP del Perú: Delito llamado de tráfico de influencias); como autores nacionales en pie a la cúspide como LEÓN TOMASTO (En: LEÓN TOMASTO, Jean Marco. (2017). Problemas sustanciales en el delito de tráfico de influencias: el bien juridico protegido y la punibilidad del tercero interesado. Revista de Derecho GACETA PENAL y PROCESAL PENAL, tomo 99, págs. 153-168) 
tipicidad de la conducta conminada legalmente, tal como lo he detallado en la doctrina citada; ergo, llamarlo delito plurisubjetivo, solo genera más confusión en su análisis, siendo correcto entenderlo como delito mono subjetivo de participación necesaria impropia, por la inminente participación y voluntad del comprador de influencias en la configuración de este hecho; y por su punibilidad al no ser víctima del delito, ni hallarse el bien jurídico protegido en la esfera personal del interesado, sino más bien en la Administración Pública.

Además, como bien detalla Reaño Peschiera (2004) (quien precisó que el delito de tráfico de influencias es un delito mono subjetivo -mas no dio detalles de la diferencia terminológica con los delitos plurisubjetivos de los delitos participación necesaria-), precisa que el delito de tráfico de influencias pertenece a los delitos de encuentro porque su dinámica comisiva exige el acuerdo de dos voluntades para consumarlo. Por una parte, el traficante invoca influencias $y$ ofrece interceder a favor del interesado ante un funcionario judicial o administrativo, a cambio de una ventaja efectiva o prometida, y de otro lado, el interesado acepta la oferta de intercesión formulada y entrega la ventaja solicitada o se compromete a entregarla.

En resumida cuenta, dada la clasificación brindada en este artículo, que ha armonizado la conceptualización de los delitos de participación necesaria y los delitos plurisubjetivos, se puede concluir con claridad y razones dogmáticas, que el delito de tráfico de influencias es un delito de participación necesaria impropiomonosubjetivo y de encuentro; puesto que:

- Su conducta no es impune al no ser el cómplice interesado una víctima del delito de tráfico de influencias.

- Su conducta no se encuentra prevista taxativamente como sucede en los delitos plurisubjetivos como si sucede con el cohecho (en nuestro Código Penal de 1991); ergo, el delito de tráfico de influencias es un delito participación necesaria impropiapero de carácter mono subjetivo.

- Al poseer el delito de tráfico de influencias una figura comisiva de dirección común de voluntades y resultados, nos hallamos ante un delito de encuentro (que por decir de más también es una especie de delitos participación necesaria) (Carrasco 2002).

\section{SOLUCIONES A LA CONTROVERSIA DOCTRINAL RESPECTO DE LA PUNIBILIDAD DEL CÓMPLICE INTERESADO EN EL DELITO DE TRÁFICO DE INFLUENCIAS}

Antes de entrar a tallar en las soluciones respecto a la controversia de la punibilidad del cómplice interesado en el delito de tráfico de influencias, es menester, hacer un recuento respecto de esta problemática en la doctrina nacional; para lo cual, se hará énfasis en las posturas adoptadas por dos referentes del derecho peruano: El profesor Julio Rodríguez (2006), quien tiene una postura en contra de la punibilidad del cómplice interesado, y el profesor José Leandro Reaño Peschiera (2004) quien defiende la tesis de este humilde autor, más fuerza las interpretaciones a un criterio de entendimiento del "injusto de la intervención" en la cual autor y partícipe contribuyen al hecho delictivo, y en donde la accesoriedad no es dependiente, es decir, el injusto del partícipe no depende del injusto del autor; cuestión que considero correcta pero no necesaria para la solución dogmática del problema de la punibilidad del cómplice interesado en el delito de tráfico de influencias (no obstante, detallar, que solo responde penalmente el cómplice interesado cuando acepta la venta de influencias o prosigue con una contraoferta, más jamás, será cómplice cuando solicite él mismo la venta de influencias, situación en la cual corresponde ser punible bajo el título de imputación de instigador).

Sin más preámbulos, es de señalar, que el profesor Julio Rodríguez (2006) (compartiendo los postulados de otros autores nacionales), precisa que no es posible la punibilidad del cómplice interesado (ciñéndose solo a la posibilidad de la punibilidad del instigador interesado); por las razones siguientes:

Resulta indiscutible que el delito de tráfico de influencias permite que puedan existir casos de complicidad, pero el comprador de influencias no puede ser considerado como la persona que auxilia o colabora dolosamente con la realización del tipo penal, pues para ello tendría que prestar auxilio al vendedor de influencias en el hecho de la negociación de estas. La 
Dogmatic reasons that justify and solve the controversy on the punibility of the "complice" interested in the crime of traffic of influences

persona que realiza la promesa o entrega el donativo, la ventaja o el beneficio al autor que no puede ser considerado cómplice del delito de tráfico de influencias. En otras palabras, el comprador de influencias o interesado no es ni coautor ni partícipe en el comportamiento típico del indicado delito. Solo la colaboración "innecesaria" o la extralimitación del rol típico merece castigo; la colaboración "necesaria" o la paramétrica dentro del rol típico es impune, salvo que esta haya sido incorporada por el legislador en un tipo penal independiente.

$\mathrm{Si}$ bien es cierto que se pone en riesgo típico el bien jurídico con la aceptación que expresa el interesado en el ofrecimiento del traficante de influencias, también lo que ese riesgo no es creado por el solicitante de influencias con la aceptación sino por el traficante con la invocación de influencias, ya que el solicitante cumple con el rol que el tipo asigna.

Si el solicitante excede su rol típico (intervención necesaria) tendrá que apreciarse en qué momento lo hace, pues si lo hace en la fase previa a la ejecución determinando el autor, responderá como instigador; si lo hace en la fase de ejecución, responderá como cómplice; y si interviene en ambos momentos de forma innecesaria, corresponderá evaluar los dos títulos de imputación para determinar el menos intenso.

Sin embargo, el profesor Reaño Peschiera (2004), precisa que si posible la punibilidad del cómplice interesado sin la necesidad de que se extralimite las conductas típicas del delito de tráfico de influencias por parte del interesado como partícipe necesario, por las razones siguientes:

El fundamento del castigo de la participación delictiva debe desligarse de la noción de accesoriedad que la concibe como dependencia de la participación del hecho del autor, debiendo ser entendida como el nexo que debe existir entre el suceso y todos los intervinientes. La construcción de la teoría de la intervención en el delito debe partir de que el hecho principal le pertenece tanto a autores como a participes, aunque en distinto grado.

La aceptación que expresa el interesado ante el ofrecimiento del traficante de influencias constituye un riesgo jurídicamente relevante e idóneo para lesionar los intereses garantizados en el precepto penal, vinculados a la credibilidad en la imparcialidad y objetividad de la Administración Pública. Si bien dicho aporte no puede dar lugar a una autoría, pues lo esencial del injusto típico solo puede ser configurado por el traficante de influencias, si debe dar lugar a una complicidad punible en el sentido que describe el artículo 25 del CP.

Teniéndose en cuenta que las posturas en contra de la punibilidad del cómplice interesado versan sobre tres hechos en esencia, y teniendo como base algunas premisas del profesor Reaño Peschiera, es de argumentar las siguientes soluciones a tal controversia:

Según la doctrinal nacional que se encuentra en contra de la punibilidad del cómplice interesado en el delito de tráfico de influencias, éste al ser partícipe necesario y al no sobrepasar la conducta típica del tipo delictivo en su conducta, es impune; empero:

Esta regla general tiene excepciones, precisamente, porque en los delitos de participación necesaria de carácter propio el partícipe necesario además de ser indispensable para la realización del tipo delictivo, es víctima del delito; por lo que hay justificación en su impunidad; situación que no sucede en el delito de tráfico de influencias, en donde el cómplice interesado no es objeto de protección por la norma penal.

Asimismo, no se ha tomado en cuenta por los autores nacionales que se encuentran en contra de la punibilidad del cómplice interesado, que en el delito de tráfico de influencias estamos ante un delito de participación necesaria de carácter impropio (conforme la clasificación brindada ut supra), en donde, si cabe la punibilidad del partícipe necesario; por darse las excepciones a la propia regla de impunidad, esto es, por no tratarse en el partícipe necesario (cómplice interesado) de una víctima del delito de tráfico de influencias, ni tampoco por tratarse de un caso en el cual el sujeto pasivo se haya en indefensión ante la acción típica del vendedor de influencias, sino más bien, tiene interés directo en el resultado a posteriori del comercio ilícito de influencias.

Las reglas de la accesoriedad limitada impiden la punibilidad de este delito; sin embargo, es de recordar: 
Que estas reglas solo provienen de una teoría que hace depender el injusto de participación al injusto de autoría, es decir, en la cual la conducta del participe solo sería punible si el autor realiza una conducta antijurídica, lo cual es correcto, empero, no se puede trivializar la conducta del participe porque implicaría una violación al principio de responsabilidad personal; ergo, armonizando conceptos, y teniéndose en cuenta que el Código Penal no establece reglas taxativas de interpretación, es factible entender que tanto autor como participe contribuyen a la realización del hecho delictivo sobre la base del riesgo que estos crean, esto es, sobre el riesgo creado al bien jurídico protegido, análisis y postura, que además de no colisionar con el principio de responsabilidad personal, es coherente con el principio de imputación objetiva (que es la forma en cómo debe analizarse una conducta delictiva según la corriente contemporánea funcionalista).

Como la conducta de aceptar la venta de influencias (por parte del cómplice interesado) no está regulada como conducta delictiva entonces no puede sancionarse su conducta, sin embargo:

Tal análisis es errado, y constituye un error de concepción (que han venido teniendo los autores nacionales), al entender al delito de tráfico de influencias como un delito plurisubjetivo cuando en realidad es un delito mono subjetivo de participación necesaria impropia, donde si cabe la punibilidad del cómplice interesado a pesar de no estar regulada su conducta taxativamente, por las razones dogmáticas ya argüidas en el capítulo anterior.

\section{Posición a partir de éste análisis}

Teniendo en cuenta la terminología correcta respecto de que constituyen delitos plurisubjetivos y delitos de participación necesaria, y la correspondiente clasificación brindada en este artículo ut supra, propongo que el cómplice interesado, es punible no solo cuando "acepta" la oferta del vendedor de influencias, sino además, cuando el vendedor de influencias realiza una oferta pero el interesado responde con una contraoferta (y viceversa), puesto que, en ambos supuestos (tanto el vendedor como el comprador de influencias) contribuyen no solo a la realización del tipo, sino también a la puesta en peligro a la administración pública, por lo que, desde un análisis de imputación objetiva sería incorrecto dejar impune la conducta de este cómplice interesado, quien además de no ser víctima de éste delito, tiene interés en que se resuelva su procedimiento administrativo o proceso judicial a su conveniencia.

En el ejemplo planteado ab initio, el interesado, quien pretendía ostentar el cargo de fiscal debería responder como cómplice primario al haber aceptado la promesa de entregarle un medio corruptor, a fin de que, a futuro, el Juez Superior venda sus influencias ante la autoridad administrativa correspondiente.

\section{CONCLUSIONES}

Aún en el supuesto de que se acepte axiomáticamente la accesoriedad limitada como regla de interpretación, esto es, respecto de la dependencia del injusto del partícipe con el injusto del autor, (y no se acepte la tesis planteada por el profesor Reaño Peschiera), nada soslaya, que, dada la clasificación brindada en este artículo, el cómplice interesado sea punible cuando "acepta" la venta de influencias realizada por el autor del delito, sobre todo, por la razón fundamental siguiente:

Al encontrarnos ante un delito mono subjetivo, únicamente puede ser autor el vendedor de influencias, ya que sobre éste (como autor) está construido el tipo penal de tráfico de influencias; ergo, es factible la aplicación de las reglas de los artículos $23^{\circ}$ al $25^{\circ}$ del Código Penal en el análisis de la punibilidad del interesado como partícipe, sin más obstáculo dogmático alguno que lo impida, puesto que, además de hallarnos ante un delito mono subjetivo, estamos ante un delito de participación necesaria pero de carácter impropio y de encuentro, en donde, la regla de impunidad deja de tener efectos para convertirse en una excepción de no punibilidad, precisamente, porque el interesado no es víctima del delito, y además no se haya en una posición de indefensión frente a la venta de influencias del traficante, sumado al argumento de que con su conducta contribuye a la creación del peligro al bien jurídico protegido, peligro abstracto que jamás existiría si es que el interesado no hubiese aceptado la compraventa de influencias. 


\section{FUENTES DE INFORMACIÓN}

\section{Fuentes bibliográficas}

Reátegui Sánchez, James (2015). Delitos contra la Administración Pública. Lima, Perú: Jurista Editores.

Salinas Siccha, Ramiro (2014). Delitos contra la Administración Pública. 3era Edición. Lima, Perú: Editorial GRIJLEY

Núñez Pérez, Fernando Vicente. (2011). La configuración típica del delito de tráfico de influencias en las Leyes $\mathrm{N}^{\circ} 29703$ y 29758. La vendita di fumo en el pacto sceleris, en Revista de Derecho Gaceta Penal, tomo 26, págs. 13-20.

Galván Ramos, Marcos Iván (2010). ¿El tráfico de influencias como modalidad del delito de estafa?: El contenido del engaño como única diferencia entre el artículo $196^{\circ}$ y la forma simulada del artículo $400^{\circ}$ del Código Penal. En Revista: La Ley en la Jurisprudencia. -Diálogo en la Jurisprudencia $\mathrm{N}^{\circ} 145-$, págs. 248-253

San Martín Castro, César/ Caro Coria, Dino Carlos/Reaño Peschiera, José. (2002). Delito de tráfico de influencias, enriquecimiento ilícito y asociación para delinquir. Aspectos sustantivos y procesales. Lima, Perú: Jurista editores.

Reaño Peschiera, José Leandro. ¿Una historia sin fin? La responsabilidad penal del interesado en el tráfico de influencias. En Revista Ius Et Veritas, edición N²8, Lima, págs. 100-121.
Carrasco Andrino, María del Mar (2002). Los delitos plurisubjetivos y la participación necesaria. Granada, España: Editorial Universidad de Alicante.

León Tomasto, Jean Marco. (2017). Problemas sustanciales en el delito de tráfico de influencias: el bien jurídico protegido y la punibilidad del tercero interesado. Revista de Derecho Gaceta Penal y Procesal Penal, tomo 99, págs. 153-168.

Quispe Aquispe, Iván. (2016). Los otros finales de la historia: el interesado como instigador en el delito de tráfico de influencias. Gaceta Penal y Procesal Penal, Lima, págs.39-62.

Reaño Peschiera, José Leandro (2001). Los delitos de corrupción de funcionarios: una visión crítica a partir del "caso Montesinos". En Revista Ius Et Veritas, edición №23, Lima, pags.283-298.

Rodríguez Delgado, Julio A. (2006). El final de la historia: ¡El interesado en el tráfico de influencias es impune!. En Revista Ius Et Veritas, edición N³3, Lima, págs.248-263.

\section{Fuentes electrónicas}

Hurtado Pozo, José (2005). Interpretación y Aplicación del art. $400 \mathrm{CP}$ del Perú: Delito llamado de tráfico de influencias. En Anuario de Derecho Penal. Recuperado del sitio de internet: https://www.unifr.ch/ddp1/ derechopenal/anuario/an_2005_12.pdf). 